\title{
The Futures of Nuclear Criticism
}

\section{Histories of nuclear criticism: the end of the world as we knew it}

The unthinkable happened at $4.20 \mathrm{pm}$ on 28 October, 1988. Though lasting only thirty-six minutes - betrayal by European NATO allies prevented escalation into the global holocaust many had feared - nuclear attack transformed the United States. As Whitley Strieber and James Kunetka record in an extraordinary travel narrative about a perilous journey around the country five years later, the United States shattered. Jeffersonian nostalgists might dream of an American revival, returning the country to its pioneer roots - a 'nation of farmers, where ... the family is the centre of things' as one woman remarks to them (Strieber and Kunetka: 127) - but Aztlan, the Hispanic Free State, is thriving within the borders of what used to be Texas, and California and the Western states, booming as they service an influx of Japanese industrialists, are agitating to cede from the Union. The dollar is unstable and Japanese yen are generally preferred. Elsewhere the British Relief provide welcome support, but the Old World can't resist the colonial impulse to inveigle its way into government and extract the country's resources. As Strieber and Kunetka's interviews with teachers, administrators, economists and others show, as the statistics they cite demonstrate, that nuclear war was unthinkable didn't matter in the end. It happened.

Except, it didn't. Except, one is tempted to say, such is the seductive power of the past, of course it didn't. Although Strieber and Kunetka's novel, Warday and the Journey Onward (1988), might be remarkable for the specificity and detail with which nuclear war is rendered - it is given a date and time; the resulting socio-economic trauma is documented in imaginary tables of statistics and transcriptions of interviews - it is entirely typical of texts from the first nuclear age in imagining a cataclysmic, jarring release to the sustained state of suspense that was the Cold War. For something so famously unthinkable, it is remarkable how many attempts there were to think a nuclear future. These fictions proliferated not only in novels of course, but also in the military games through which nuclear futures were fought out, in civil defence planning for post-war reconstruction and, not least, in the nuclear futures exploding in people's dreams. They also became mundanely part of everyday life and popular culture - in board games like Apocalypse, for instance.

From the perspective of the twenty-first century, and with the benefit of hindsight, such visions seem almost quaint. The mode of our remembering might even be nostalgic. Indeed, the past becomes attended by an aura of inevitability. We should, of course, resist the impulse to view it in this way. It emerges from a solipsistic view of the present, turning history into a series of inevitable steps toward a single, predetermined outcome. It renders history cosy and safe and stops us engaging with the lived experience of the past and the multiple potential futures encoded within it.

This is particularly important for nuclear studies. Most of this article is about the futures of nuclear criticism, but to deal with these we must attend to the past: it is an historicist criticism as well as a futurist one and these two modes are intimately bound up with one another, for our stories about the nuclear past become stories about our nuclear futures. The Cold War is the first clearly defined period of the nuclear age and to treat its outcome as the only possible one is to underwrite the 
fallacy both that nuclear weapons kept the peace and that, therefore, they can be expected so to do in the future. That they deterred certain kinds of war, slowing the rhythms of global conflict, might - might - be true, but as any statistician will tell you, one iteration of a sequence is a poor predictor of future events. As Martin Amis put it in 'Thinkability,' the introduction to his short story collection, Einstein's Monsters (1987), 'the trouble with Deterrence is that it can't last out the necessary timespan, which is roughly between now and the death of the sun' (Amis, 16-17).

Hence, in its historicist mode, nuclear criticism should treat past imaginations of nuclear futures with seriousness and without condescension. It should do this not only because they might speak still to our nuclear futures, but also because the history of things that didn't happen and of the cultural and social consequences of their not happening is an important one. This need not mean adopting an apocalyptic perspective. Indeed, a serious nuclear studies engages the complex range of our nuclear pasts and futures. In its historical mode this means, for instance, resisting the impulse to assume that Cold War nuclear fear was experienced universally and traumatically; in its futurist mode, it is to acknowledge the range of potential nuclear futures, some of which may indeed be apocalyptic, but in many of which nuclear technologies will persist more mundanely.

\section{Futures of nuclear criticism}

These issues of our nuclear pasts and futures seem particular resonant in a contemporary moment in which the idea of the Anthropocene is gaining critical currency. There is interest in the concept partly because the Anthropocene Working Group is currently formulating a proposal, for consideration by the International Commission on Stratigraphy, to formalise the Anthropocene within the geological time scale, but it is also because the concept of the Anthropocene speaks more broadly to our sense of the critical impact on the planet of a human presence. This impact is cross-disciplinary and extends beyond the Academy. The journal, The Anthropocene Review, for instance, puts research in the sciences alongside that in the humanities, the Nottingham Contemporary gallery has recently laid on free study sessions on the Anthropocene in the Midlands and Robert Macfarlane, one of Britain's great nature writers, has published a major essay on the subject in The Guardian.

Perhaps, surprisingly, the relevance of the Anthropocene to nuclear studies isn't particularly because the radionuclides blown around the globe by nuclear weapons tests may be the preferred markers of the proposed new epoch (this is something currently being debated), though they are certainly symbolically resonant. It is because the questions posed by the Anthropocene speak in profound ways to those nuclear criticism tackles.

An exceptionalist discourse has, since at least 1945, been used to narrate nuclear technology. Rightly or wrongly, it has been imagined as being of a different order to other technologies, bound up, in the stories we tell about it, with our greatest hopes and anxieties about how the things we make shape and define us. Technology is 
always cultural; nuclear technology, such is its symbolic resonance, more intensively so.

From the beginning it has been double-coded as both the greatest intellectual triumph and as that which is most revealing of human destructive impulses. On the day on which Hiroshima was levelled (an event that led very quickly to speculation about the potential for nuclear weapons to be civilisation-ending), President Harry Truman described atomic technology as 'harnessing the basic power of the universe' and ushering in a 'new era in man's understanding of nature's forces.' It is no wonder that the Promethean myth has been so resonant in nuclear narratives.

Like the Anthropocene, nuclear technology makes us think about questions that address what it is to be human and how we mesh into, are shaped by and influence the larger ecosystems of which we are a part:

- How and how quickly does our presence on the planet change it? In other words, what will our human legacy to the planet be?

- What agency do we have to shape these changes?

- More existentially, given the larger timescales with which the Anthropocene puts us in touch and the ways in which nuclear fictions sometimes ask us to imagine the end of human existence on Earth, what is the meaning, if any, of human life on this planet?

I suggest three problematics that could form the basis for an engaged, twenty-first century nuclear criticism: nuclear temporalities, nuclear geographies and nuclear subjectivities. In each of these areas the effects of nuclear technologies and materials - and, perhaps as importantly, of how they have been imagined - have been to unsettle our sense of our human place in the world. By addressing these areas nuclear criticism can engage with the profoundly disruptive ways in which nuclear culture structures our imagination in what we might call the dawning of a long Modernity, measured by the slow ticking in deep time of the Anthropocene and its legacies.

I suggest, too, the tentative beginnings of a lexicon with which to interrogate these problematics. While the words and phrases suggested for this lexicon are ones I have found useful in thinking through nuclear culture, needless to say they may not suit everyone's purposes and there is, of course, scope to supplement the list.

\section{Nuclear Temporalities}

The narration of nuclear events often disrupts the timescales within which we commonly understand human lives. On the one hand, nuclear moments - typically, the nuclear explosion or the radiation lab accident - are imagined as instantaneous and world-ending. This was a particular feature of the Cold War imagination in which nuclear disaster, usually war, was expected to be delivered out of the blue and to change the world entirely. Images that crop up frequently are the blinding flash of light and the stopped clock, conveying the sudden, jarring transition from the quotidian to the extraordinary. 
On the other hand, they provoke us to think of timescales stretching beyond those through which we normally measure our significance: of human civilisations; of the species; even of the planet. These might be changes imagined to be wrought in cataclysmic nuclear moments (the shattered ecosystems following nuclear war, for instance) or they might result from the slower, more insidious effects of the 'legacy waste' we bequeath to the planet. Such longer timescales might be experienced in the contemporary moment, as in Bobbi Ann Mason's novel of nuclear health scares at a uranium reprocessing plant, An Atomic Romance (2006); be imagined in the longer environmental legacies of a human presence, like those that appear in Ursula Le Guin's extraordinary Always Coming Home (1985); or be imagined in the longer futures explored in Michael Madsen's documentary film, Into Eternity (2010), about the Onkalo repository for spent nuclear fuel, in which he asks what it means to build an architecture to store waste for a hundred thousand years (what architecture has ever lasted that long? how would we communicate the dangers it houses to future generations? what, even, would it mean to be human in five thousand, ten thousand or a hundred thousand years?).

Oscillating between the sudden traumas of nuclear moments and the vertigo-inducing chasms of geological time, nuclear narratives wrench us from the arcs of ordinary human lifetimes through which we normally understand reality. They shake our sense of our significance.

\section{Toward a lexicon for nuclear criticism:}

- Anthropocene - the idea (currently under investigation) that human presence is so significantly changing the planet that it should name the current geological epoch. Radionuclides from nuclear weapons testing might provide markers for the Anthropocene, but perhaps more significant for nuclear criticism is that both the Anthropocene and nuclear culture may challenge us to think of the place of humans within deep time.

- archive (Derrida 1984) - the written and other records in which what it means to be human is encoded, the destruction of which is a more profound conceptual threat to human being than deaths of individual humans.

- slow violence (Nixon 2011) - the gradual processes of environmental violence, taking place across timescales we struggle to encode in narrative and impacting unevenly on communities around the planet. The most obvious nuclear contexts for slow violence are waste and fallout.

- states of suspense (Cordle 2008) - the experience of living in extended anticipation of nuclear calamity, most obviously a psychological phenomenon during the Cold War but persisting, rightly or wrongly, in continuing consciousness of living in anticipation of significant nuclear moments.

\section{Nuclear Geographies ${ }^{1}$}

Just as nuclear temporalities disrupt our sense of time, nuclear geographies challenge how we experience place and space. This might be, as it was for the Cold War 
imagination and as I have discussed elsewhere, how symbolically significant places the home; the city; the planet - are conceived as potentially nuclear, transformed by blast, heat or radiation. More profoundly, though, it is the experience or imagination of nuclear effects transgressing boundaries separating one place from another. This could be the penetration of radiation through materials that appear solid to the eye, the dissemination of radioactive fallout throughout and between ecosystems by climatic and other processes, or simply the suspicion that something like this is taking place. In Maggie Gee's novel, Grace (1988), for instance, Grace's sense of place is transformed when she listens to news reports from Chernobyl. Suddenly, her cosy home in Britain 'becomes' nuclear, traversed, in her mind at least, by contaminants travelling vectors between the domestic and the industrial: 'Was it really there then, the radiation, that nervous, whispering spring? Was it in the ordinary leaves and the ordinary milk at breakfast?' (Gee: 2). For all that this emerges from the exceptional circumstances of the Chernobyl disaster, it is a revelation of the nuclear everyday, an understanding of the ubiquity in 'ordinary' environments, objects and foodstuffs of a nuclear presence.

In particular, nuclear geographies alert us to the scaling by which local and global interconnect, potentially tying those separated by boundaries otherwise imagined as absolute, into a common fate. To this extent nuclear geographies are illustrative of the power of the ecological imagination to help us understand the interconnection of human, industrial and natural worlds.

\section{Toward a lexicon for nuclear criticism:}

- dead city, the (Vanderbilt 2002) - one of a number of symbolically significant nuclear places, in this instance signalling the haunting of urban experience after the 1945 atomic attacks on Japan when other cities became imagined as potential 'Hiroshimas.'

- nuclear sublime (Hales 1991) - though specifically rooted, in Hales's analysis, in the US experience of bomb testing, the nuclear sublime provides a more generally useful concept for conceptualising the relations between technological and natural sublimes, and a tool for thinking how nuclear events challenge and exceed the imagination and may be domesticated into narratives that make them 'safe.'

- toxic discourse (Buell 1998) - narrative that describes the interpenetration of human and 'natural' environments and chart how we understand ourselves within them.

\section{Nuclear Subjectivities}

As with nuclear geographies, a key motif in our understanding of nuclear subjectivities - of the ways in which we imagine ourselves as nuclear - is the transgression of boundaries, in this case those we imagine separating us from the world through which we move. It is a trauma of discreteness: a rupturing of the psychological illusion by which we think of ourselves as self-contained units, rather 
than as ecologies in permanent exchange with the ecosystems through which we pass and that pass through us.

Most frequently this is apparent in narratives that deal with real or imagined encounters with radiation. In 'The Aftermath,' a chapter added for the fortieth anniversary edition of John Hersey's Hiroshima (1946; 1985), it becomes clear not only how the bodies of many hibakusha, 'explosion-affected persons' (Hersey: 120), were shaped by radioactive legacies, but also how their personal, social and working lives were forged by changed perceptions of them following their encounter with the atomic bomb.

These subjectivities imply, then, both nuclear physiologies (as, for instance, when strontium-90, a by-product of weapons testing, is found in children's milk teeth) and nuclear psychologies (how we imagine ourselves to be different because of possible encounters with nuclear materials or events). In her discussion of the atomic American West in Savage Dreams (1994), Rebecca Solnit describes visiting a peace camp to participate in a trespass at a nuclear weapons testing site. She 'remembered', she said, 'to be afraid of the dust, the dust that might be radioactive' (Solnit: 4). The formulation is important here: fear is meant to be instinctive, an immediate physiological response to physical threat. Instead, it becomes, such is the disconnect induced when we are threatened by dangers our senses are unable to detect, a conscious act, a forcing of instinct.

\section{Toward a lexicon for nuclear criticism:}

- nuclear uncanny (Masco 2005) - the eerie shimmering of everyday experience when we become conscious of nuclear contexts (as, for instance, when potential radioactive contamination makes us distrust our senses' capacity to inform us about the state of our bodies and of the environment).

- nuclearity (Hogg 2012) - the mobile and context-dependent assumptions people make about nuclear dangers.

- politics of vulnerability (Cordle 2012) - the appropriation of vulnerability to nuclear events and effects (and, more broadly, the nuclear state) for the purposes of political action, frequently in ways that oppose the logics of violence by which power operates. Drawing attention to one's fragility in the face of nuclear risk provides a means of forging a common identity across lines of demarcation (political boundaries; physical separation) that might otherwise leave people separated one from another.

- transmutation (Weart 1988) - the logic underpinning nuclear imagery, describing the power of nuclear technology, materials and events to unsettle our sense of fixed, unchanging categories.

\section{Conclusion: mapping nuclear culture}

Attending to these problematics allows us to engage with the ways in which our world is mundanely and comprehensively nuclear - how it doesn't only 'become' nuclear in exceptional circumstances. It provides the outline of a map on which to chart the 
cultural ramifications of what Joseph Masco has called the 'plutonium economy' (Masco: 38) manifested (though the word suggests a visibility perhaps inappropriate to the disguise and secrecy that often accompany nuclear phenomena) in mining, industrial infrastructure, financial speculation and investment, nuclear energy production, weapons production and deployment, waste management and environmental containment and contamination.

\section{Works Cited}

Amis, Martin. Einstein's Monsters. London: Vintage, 2003.

Buell, Frederick. 'Toxic Discourse'. Critical Inquiry 24.3 (1998): 639-65.

Cordle, Daniel. States of Suspense: The Nuclear Age, Postmodernism, and United States Fiction and Prose. Manchester: Manchester University Press, 2008.

—. 'Protect/Protest: British Nuclear Fiction of the 1980s.' The British Journal For the History of Science 45.4 (2012): 653-69.

Derrida, Jacques, 'No Apocalypse, Not Now (Full Speed Ahead, Seven Missiles, Seven Missives)', Diacritics 14.2 (1984): 20-31.

Hales, Peter B. 'The Atomic Sublime'. American Studies 32.1 (1991): 5-31.

Hersey, John. Hiroshima. Rev. ed. London: Penguin, 1985.

Hogg, Jonathan. "'The Family That Feared Tomorrow”: British Nuclear Culture and Individual Experience in the Late 1950s.' The British Journal For the History of Science 45.4 (2012): 535-49.

Le Guin, Ursula. Always Coming Home. London: Grafton, 1986.

Madsen, Michael (dir.). Into Eternity. Denmark, 2010.

Mason, Bobbi Ann. An Atomic Romance. New York: Random House, 2005.

McFarlane, Robert. 'Generation Anthropocene: How Humans Have Altered the Planet Forever', The Guardian [online] 1 April 2016 http://www.theguardian.com/books/2016/apr/01/generation-anthropocenealtered-planet-for-ever

Nixon, Rob. Slow Violence and the Environmentalism of the Poor. Cambridge: Harvard University Press, 2011. 
Silko, Leslie Marmon. Ceremony. New York: Penguin, 1986.

Solnit, Rebecca. Savage Dreams: A Journey into the Landscape Wars of the American West. Berkeley: University of California Press, 1999.

Strieber, Whitley and James Kunetka. Warday and the Journey Onward. London: Coronet, 1985.

Truman, Harry. Statement by the President of the United States. August 6, 1945. http://www.pbs.org/wgbh/americanexperience/features/primaryresources/truman-hiroshima/

Vanderbilt, Tom. Survival City: Adventures Among the Ruins of Atomic America. New York: Princeton Architectural Press, 2002.

Weart, Spencer. Nuclear Fear: A History of Images. Cambridge: Harvard University Press, 1988.

[Note:]

${ }^{1}$ I am indebted to a former colleague, James Holden, who used this term when we discussed the anxious nuclear spaces of the American Southwest in teaching Leslie Marmon Silko's Ceremony (1977). 